\title{
Detecção de riquétsias em carrapatos do gênero Amblyomma (Acari: Ixodidae) coletados em parque urbano do município de Campinas, SP
}

\author{
Rickettsiae detection in Amblyomma ticks (Acari: Ixodidae) \\ collected in the urban area of Campinas City, SP
}

\author{
Dora Amparo Estrada1, Teresinha Tizu Sato Schumaker², Celso Eduardo de Souza ${ }^{3}$, \\ Elias José Rodrigues Neto ${ }^{3}$ e Arício Xavier Linhares ${ }^{1}$
}

\begin{abstract}
RESUMO
o Município de Campinas situa-se em região endêmica para febre maculosa brasileira do Estado de São Paulo, onde vários casos desta doença vem ocorrendo. Capivaras têm sido associadas ao ciclo dessa riquetsiose por apresentarem sorologia positiva e serem hospedeiras de carrapatos Amblyomma spp principais vetores da doença. Carrapatos foram coletados no parque urbano do Lago do Café, Campinas, SP, local associado a casos humanos suspeitos de febre maculosa brasileira, sobre a vegetação e das capivaras ali presentes, e pesquisados quanto à presença de riquétsias pela reação em cadeia da polimerase e pelo teste de hemolinfa. Adultos de Amblyomma cajennense e Amblyomma cooperi albergavam Rickettsia bellii, não patogênica, identificada pela análise das seqüências de nucleotídeos do gene gltA, porém, não foram constatadas riquétsias do Grupo da Febre Maculosa. Estes resultados associados à ausência de um isolado de riquétsias do Grupo da Febre Maculosa de capivaras indicam que seu papel, enquanto reservatório, necessita de maior investigação.
\end{abstract}

Palavras-chaves: Febre maculosa brasileira. Amblyomma spp. Rickettsia bellii. Genes Glt $A$.

\begin{abstract}
The city of Campinas is located in an endemic area for Brazilian spotted fever in São Paulo State, where several cases have recently occurred. Capybaras have been associated with the cycle of this disease, for they present positive serology and serve as host for ticks of the genus Amblyomma, the main vectors of brazilian spotted fever. Ticks were colleted both from Capybaras and from the vegetation in the city park Lago do Café, located in the urban area of Campinas City, SP, a site associated with suspected human cases of brazilian spotted fever. The ticks collected were examinaded for the presence of rickettsiae using polymerase chain reaction and the haemolymph test. Through analysis of the gene glt $A$ nucleotide sequence, adults of Amblyomma cajennense and Amblyomma cooperi were found to be infected with the non pathogenic Rickettsia bellii. However, no rickettsiae of the Spotted Fever Group were detected. These results indicate that the role of capybaras as reservoirs of rickettsiae of the Spotted Fever Group is still uncertain and further studies are required.
\end{abstract}

Key-words: Brazilian Spotted Fever. Amblyomma spp. Rickettsia bellii. GltA gene.

A febre maculosa brasileira (FMB), causada por riquétsias do grupo da febre maculosa e transmitida por carrapatos ${ }^{5}$, é similar à febre maculosa das montanhas rochosas que tem como agente Rickettsia rickettsii. A FMB é notificada principalmente na região Sudeste do país, com destaque para os Estados de Minas Gerais ${ }^{789}$ e São Paulo ${ }^{4151821}$.
Na biossistemática moderna, a análise comparativa das seqüências de nucleotídeos do DNA de vários genes tem contribuído de forma fundamental para a identificação e caracterização das espécies de riquétsias. Atualmente, reconhecem-se várias espécies do gênero Rickettsia (Rickettsiales: Rickettsiacea) que estão divididas basicamente

\footnotetext{
1. Departamento de Parasitologia do Instituto de Biologia da Universidade Estadual de Campinas, Campinas, SP. 2. Departamento de Parasitologia do Instituto de Ciências Biomédicas da Universidade de São Paulo, São Paulo, SP. 3. Laboratório de Carrapatos da Superintendência de Controle de Endemias, São João da Boa Vista, São João da Boa Vista, SP. Auxilio: FAPESP processo 02/02471-6

Endereço para correspondência: Dr. Arício Xavier Linhares. Dept ${ }^{\circ}$ de Parasitologia/IB/UNICAMP. Caixa Postal 6109, 13083-970 Campinas, SP

Tel: 5519 3788-6292; Fax: 5519 3289-3124.

e-mail: aricio@unicamp.br

Recebido para publicação em 7/5/2004

Aceito em 14/11/2005
} 
no Grupo do Tifo (GT) e Grupo da Febre Maculosa (GFM). 0 GT é composto por duas espécies causadoras de tifos em humanos. No GFM, mais de 14 espécies válidas foram assinaladas, além de outras não reconhecidas ${ }^{28}$. Entretanto, no Brasil pouco se conhece sobre a identificação específica das riquétsias que aqui circulam.

o Município de Campinas do Estado de São Paulo, assim como vários outros adjacentes, situa-se em uma área endêmica para FMB aonde vários casos fatais foram assinalados ${ }^{416}$. Além dos casos ocorridos em áreas rurais, outros casos, suspeitos ou confirmados, foram registrados na zona urbana ${ }^{4}$.

A FMB é transmitida para o homem por carrapatos, principalmente do gênero Amblyomma, e tem como potenciais reservatórios vários grupos de mamíferos ${ }^{15}$. Na região de Campinas, as capivaras ocorrem em abundância, vivendo em ecótopos alterados pelo homem e têm sido relatadas com sorologia positiva para riquétsias do $\mathrm{GFM}^{15}$. Poderiam, ainda, exibir riquetsemia ${ }^{30}$, o que nesse caso evidenciaria seu potencial como fonte de infecção para carrapatos. 0 certo até o presente momento é que estes animais constituem hospedeiros de Amblyomma cooperi e Amblyomma cajennense, elevando as densidades destes carrapatos em sítios onde se encontram estabelecidos (CE Souza, EJR Neto: dados não publicados). Amblyomma cooperi foi observado carreando riquétsias, inclusive do $\mathrm{GFM}^{131417} \mathrm{e}$ embora possam parasitar outros mamíferos, principalmente em seus estádios imaturos, raramente picam humanos. Amblyomma cajennense é incriminado como principal transmissor da $\mathrm{FMB}^{5}$. Todos estes fatos sugerem um possível papel das capivaras no ciclo da FMB porém, até o momento, não existem isolados de riquétsias a partir destes animais.

Tendo em mente a obtenção de novas evidências sobre 0 papel das capivaras como reservatórios de riquétsias do GFM, carrapatos foram coletados no Lago do Café, zona urbana de Campinas, tanto sobre a vegetação como nas capivaras ali presentes. Este parque está associado a casos suspeitos de FMB.

\section{MATERIAL E MÉTODOS}

As coletas de carrapatos de vida livre foram realizadas no Lago do Café (22052'14"S e 4702'52"W), área urbana de Campinas, Município do Estado de São Paulo. A vegetação próxima ao sítio de estabelecimento de capivaras (Hydrochaeris hydrochaeris) lá presentes foi rastreada (25/09/2001), utilizando-se do arraste de flanela $(1,5 \times 1,0 \mathrm{~m})$ e de armadilhas de gelo seco. Após identificação $0^{212}$ os carrapatos, ainda vivos, foram crio-preservados $\mathrm{a}-70^{\circ} \mathrm{C}$. Posteriormente (26/03/2002), foram coletados carrapatos sobre oito capivaras com sorologia positiva para FMB (CE Souza, EJR Neto: dados não publicados) e os exemplares de $A$. cooperi foram utilizados no presente estudo. Estes exemplares foram incubados por um período de sete dias sob temperatura e umidade relativa controladas, $30^{\circ} \mathrm{C}$ e $80 \%$ respectivamente, em câmara climática modelo FANEM 347. Após incubação, identificação e extração de hemolinfa os exemplares foram preservados em etanol absoluto. Com a hemolinfa, obtida pela secção da parte distal de uma das patas, foram feitos esfregaços associados à coloração de Gimenez ${ }^{11}$ e analisados para detecção de bactérias intracelulares ${ }^{3}$.

Para realização da reação em cadeia da polimerase, procedeu-se à extração do DNA total ${ }^{1}$ dos carrapatos. Os adultos foram processados individualmente e as ninfas em lotes de 20 exemplares cada um. Nas reações, foram utilizadas as condições e pares de iniciadores previamente descritos. 0 par gêneroespecífico $R p C S .877$ e e $R p C S .1258 n^{27}$, amplifica um fragmento de 381 pares de base ( $\mathrm{pb})$ do gene gltA que codifica a enzima citrato sintase de Rickettsia spp. Pode-se afirmar que o gene gltA permite a detecção de todos os organismos do gênero Rickettsia e não foi preciso utilizar o par de iniciadores do gene $O m p B$, uma vez que o material foi seqüenciado para identificação específica. Nas reações para detecção de Rickettsia spp do Grupo da Febre Maculosa foi utilizado o par $R r 190.70$ p e $R r .701 n^{28}$ que amplifica um fragmento de $632 \mathrm{pb}$ do gene OmpA, que codifica uma proteína externa de membrana de $190 \mathrm{kDa}$.

Como controle positivo, utilizou-se DNA genômico de Rickettsia montanensis (GFM, não patogênica) e como negativo, água estéril.

As reações de seqüenciamento foram realizadas com um kit comercial (BigDye TM Terminator-Cycle Sequencing Ready Reaction-Applied Biosystems), utilizando os iniciadores empregados na PCR e um seqüenciador automático (ABI PRISM 377 DNA Sequencer - Perkin Elmer). As seqüências de nucleotídeos obtidas foram alinhadas (pacote CLUSTAL) e comparadas com as seqüências do mesmo gene descritas para espécies de riquétsias disponíveis no GenBank, e as percentagens de similaridade foram determinadas (pacote PC/GNE).

\section{RESULTADOS}

No total, foram processados 1.783 carrapatos para pesquisa dos genes gltA e ompA, através de PCR. Destes, 1708 exemplares foram coletados sobre a vegetação (236 machos e 276 fêmeas de Amblyomma cajennense; 56 machos de Amblyomma cooperi e 1.140 ninfas de Amblyomma spp) e 75 sobre capivaras (machos de A. cooperi). Nove amostras amplificaram o fragmento esperado para o gene gltA: 5 fêmeas A. cajennense (da vegetação) e 04 machos A. cooperi (das capivaras), com uma taxa de infecção de 1,4\% do total de adultos examinados e de 5,3\% dos coletados nas capivaras. Nenhuma das amostras foi positiva para o gene ompA. Todos os fragmentos amplificados tiveram as duas fitas do DNA seqüenciadas que apresentaram similaridade com as sequiências de nucleotídeos de Rickettsia bellii (GenBank U59716), com percentuais de similaridade entre 96 e $99 \%$.

$\mathrm{Na}$ prova da hemolinfa, realizada com os 75 exemplares A. cooperi coletados sobre capivaras, 36\% apresentaram elementos com morfologia e coloração semelhantes a riquétsias, dois dos quais, confirmados por PCR. Nesta prova, dois exemplares PCR positivos apresentaram-se negativos. 


\section{DISCUSSÃO}

No presente trabalho, foram realizadas coletas de carrapatos sobre a vegetação do Lago do Café, do Município de Campinas, SP, endêmico para FMB, bem como sobre capivaras ali presentes, soropositivas para riquétsias (CE Souza, EJR Neto: dados não publicados). Este parque está associado a casos suspeitos de FMB de origem urbana e visitantes e funcionários estão sujeitos a constantes picadas por carrapatos.

Entre os carrapatos coletados foram identificados adultos de A. cajennense e de A. cooperi, além de ninfas Amblyomma spp, já assinaladas por outros autores nesta regiã $0^{418}$. Nove adultos (A. cajennense da vegetação e de A. cooperi de capivara) amplificaram o fragmento do gene gltA, enquanto as demais amostras foram negativas para os dois genes investigados (ompA e gltA). A ausência de ninfas de Amblyommaspp positivas foi também notada em outra pesquisa realizada na região, com emprego de biologia molecular ${ }^{13}$. É possível que os adultos, em função do maior número de repastos sanguíneos exercidos ao longo de suas vidas, tenham maior chance de serem encontrados infectados.

Em todas as amostras as sequiências de nucleotídeos do fragmento do gene gltA, gênero-específico, mostraram similaridade com Rickettsia bellii (GenBank U59716). Até o momento, esta bactéria, por ainda não ter sido encontrada em humanos, tem sido considerada não patogênica. Esta espécie tem a peculiaridade de não se classificar dentro do GFM ou GT; é tida como provável ancestral das riquétsias pertencentes dos dois grupos clássicos ${ }^{29}$.

Rickettsia bellii foi também observada em $A$. cajennense coletados no Parque Hermógenes Leitão Filho - Cidade Universitária, Campinas, $\mathrm{SP}^{6}$ e em A. cooperi capturados no Município vizinho de Pedreira ${ }^{1314}$. É possível que esta espécie esteja amplamente distribuída no Brasil, pois já está registrada também na região Norte, em Amblyomma humerale e Amblyomma oblongoguttatum ${ }^{10}$.

Amblyomma cajennense, carrapato que mais ataca o homem no Brasil, é incriminado como o principal transmissor da FMB5 No Estado de São Paulo, um isolado deste carrapato foi tipificado como pertencente ao sorotipo $R$. rickettsii ${ }^{24}$ e, especificamente na região de Campinas, foram registrados exemplares positivos para 0 gene ${ }_{0} m p \mathrm{~A}^{22}$ de riquétsias do GFM, o que não pode ser confirmado no presente estudo. Isto talvez possa ser explicado como uma decorrência da competição entre diferentes espécies de Rickettsia no estabelecimento dentro do vetor; a primo-infecção por uma espécie pode dificultar o estabelecimento de uma segunda ${ }^{19}$. Estudos recentes tem levado à especulação de que esta competição favoreça infecções por riquétsias não patogênicas, com transmissão vertical, o que pode explicar parcialmente a baixa prevalência de $R$. rickettsii nos carrapatos na natureza.

As capivaras do Lago do Café encontram-se habitualmente infestadas por adultos $A$. cajennense e $A$. cooperi, além dos imaturos do mesmo gênero (CE Souza, EJR Neto: dados não publicados). Machos de $A$. cooperi coletados sobre elas, além de submetidos a PCR, tiveram suas hemolinfas examinadas, após coloração com Gimenez. Nesta prova, 36\% dos exemplares apresentaram elementos com coloração e morfologia semelhantes a riquétsias, enquanto que por PCR apenas 5,3\% amplificaram o fragmento do gene gltA.

Esta diferença entre os resultados obtidos se deve à maior sensibilidade e especificidade da PCR que, além disto, confere resultados mais rápidos ${ }^{61322}$ em relação ao teste da hemolinfa. Este teste associado ao corante de Gimenez, por seu baixo custo, é muito utilizado em pesquisas em regiões onde a prevalência das riquétsias é baixa ou desconhecida, envolvendo grande número de carrapatos a serem processados. Entretanto, ele apresenta elevado grau de dificuldade para a distinção entre os organismos intracelulares. Outras bactérias Gram-negativas também podem ser coradas ${ }^{11}$ e a variabilidade morfológica exibida por Rickettsia spp na dependência da temperatura ${ }^{25}$ podem conduzir a erros de interpretação. Para melhor discriminação deste grupo de bactérias, recomenda-se uma associação do teste da hemolinfa com anticorpos fluorescentes ${ }^{3}$ que, infelizmente, raramente se encontram disponíveis.

É importante salientar que além dos resultados falsos positivos já esperados, também foram detectados na prova da hemolinfa falsos negativos. Assim, um especial cuidado dever ser tomado quando do uso desta metodologia na triagem de carrapatos para avaliação de áreas de riscos para FMB, pois, exemplares positivos podem ser excluídos de testes mais específicos.

Há indicativos de que as capivaras atuem como reservatório de riquétsias do $\mathrm{GFM}^{15}{ }^{17}$. Porém, no presente estudo não foi possível colher evidencias em favor desta hipótese.

Embora estudos sobre infecções experimentais em animais de laboratório com isolados de humanos e imunohistoquímicos em tecidos de necropsia de humanos ${ }^{20} 16$ indiquem Rickettsia rickettsii como causadora da FMB na região em estudo, há apenas um isolado humano caracterizado através do seqüenciamento de gene ompB confirmando sua presença como agente causal da doença ${ }^{22}$. No Brasil, uma outra riquétsia do GFM patogênica, Rickettsia felis, foi notificada em pacientes no Estado de Minas Gerais ${ }^{26}$ e em pulgas nos Estados de São Paulo e Minas Gerais ${ }^{13}$, oriundos de áreas endêmicas para FMB.

Em síntese, fica evidente que muito ainda há a ser esclarecido acerca do ciclo das riquetsioses no Brasil, tanto quanto em relação à adequada caracterização das espécies/ cepas circulantes quanto ao efetivo papel dos potenciais reservatórios e vetores da doença.

\section{AGRADECIMENTOS}

Ao Prof. Juan Pablo Olano, Medical Branch-Texas University - EUA, pelo DNA genômico de $R$. montanensis fornecido, assim como também os iniciadores $17 \mathrm{kDa}$ utilizados para testes preliminares. Ao Prof. José de la Fuente, Department of Veterinary Pathobiology, Center for Veterinary Health Sciences, Oklahoma State University, Stillwater, OK, EUA, pelo fornecimento dos iniciadores do gene OmpA utilizados para testes preliminares. 


\section{REFERÊNCIAS BIBLIOGRÁFICAS}

1. Aljanabi SM, Martinez I. Universal and rapid salt-extraction of high quality genomic DNA for PCR-bases techniques. Nucleic Acids Research 25: 4692$4693,1997$.

2. Aragão H, Fonseca F. Notas de Ixodología. VIII. Lista e chave para os representantes da fauna ixodológica brasileira. Memórias do Instituto Oswaldo Cruz 59: 115-148, 1961.

3. Burgdorfer W. Hemolymph test. A technique for detection of Rickettsiae in ticks. Journal Tropical of Medicine and Hygiene 19: 1010-1014, 1970.

4. Centro de Vigilância Epidemiológica Prof. "Alexandre Vranjac”, Secretária de Estado da Saúde. Informe técnico Febre Maculosa Brasileira. São Paulo, 2002

5. Dias E, Martins AV. Spotted fever in Brazil. American Journal of Tropical Medicine 19: 103-108, 1939.

6. Estrada DA. Aplicação da Reação em Cadeia pela Polimerase para detecção de riquétsIas em carrapatos (Acari: Ixodidae) coletados no Município de Campinas, SP. Tese de Mestrado do Departamento de Parasitologia do Instituto de Biologia da Universidade Estadual de Campinas, Campinas, SP, 2003.

7. Galvao MA, Calic SB, Chamone CB, Mafra S CL, Cesarino Filho G, Olano JP, Walker DH. Spotted fever rickettsiosis in Coronel Fabriciano, Minas Gerais State. Revista da Sociedade Brasileira de Medicina Tropical 36: 479-481, 2003.

8. Galvão MA, Dumler JS, Mafra CL, Calic SB, Chamone CB, Cesarino Filho G, Olano JP, Walker DH. Fatal spotted fever rickettsiosis, Minas Gerais, Brazil. Emerging Infectious Diseases 9: 1402-1405, 2003.

9. Galvão MA, Lamounier JA, Bonomo E, Tropia MS, Rezende EG, Calic SB, Chamone CB, Machado MC, Otoni ME, Leite RC, Caram C, Mafra CL, Walker DH. Riquettsioses emergentes e reemergentes numa região endêmica do Estado de Minas Gerais, Brasil. Cadernos de Saúde Publica 18:1593-1597, 2002.

10. Gehrke FS. Estudo da prevalência de Borrelia spp, Ehrlichia spp e Rickettsia spp em carrapatos coletados no Estado de São Paulo. Dissertação de Mestrado - Departamento de Parasitologia do Instituto de Ciências Biomédicas da Universidade de São Paulo, São Paulo, SP, 2002.

11. Giménez DF. Staining rickettsiae in yolk sacs cultures. Stain Technology 39: 135-140, 1964.

12. Guimarães JH, Tucci EC, Barros-Battesti DM. Ectoparasitas de importância veterinária. Plêiade/Fundação de Amparo a Pesquisa de São Paulo, 2001.

13. Horta MC. Pesquisa de infecção por riquétsias do grupo da Febre Maculosa em humanos, eqüídeos, caninos e diferentes estádios de vida de Amblyomma cajennense, provenientes de uma área endêmica do estado de São Paulo. Tese de Mestrado, Universidade de São Paulo, São Paulo, SP, 2002.

14. Labruna MB, Whitworth T, Horta MC, Bouyer DH, McBride JW, Pinter A, Popov V, Gennari SM, Walker DH. Rickettsia species infecting Amblyomma cooperi ticks from an area in the State of São Paulo, Brazil, where Brazilian Spotted Fever is endemic. Journal of Clinical Microbiology 42: 90-98, 2004

15. Lemos ERS. Rickettsial Diseases in Brazil. Virus Reviews and Research 7: 7-16, 2002

16. Lemos ERS, Alvarenga FBF, Cintra ML, Ramos MC, Paddock CD, Ferebee TL, Zaki SR, Ferreira FCC, Ravagnani RC, Machado RD, Guimarães MAAM, Coura JR. Spotted fever in Brazil: A soroepidemiological study and description of clinical cases in an endemic area in the State of São Paulo. American Journal of Tropical Medicine and Hygiene 65: 329-334, 2001.

17. Lemos ERS, Melles HHB, Colombo S, Machado RD, Coura JR, Guimarães MAA, Sanseverino SR, Moura A. Primary isolation of Spotted Fever Group Rickettsiae from Amblyomma cooperi collected from Hydrochaeris hydrochaeris in Brazil. Memórias do Instituto Oswaldo Cruz 91: 273-275, 1996.

18. Lima VLC, Figueiredo AC, Pignatti MG, Modolo M. Febre Maculosa no Município de Pedreira-Estado de São Paulo, Brasil. Relação entre ocorrência e parasitismo humano por ixodídeos. Revisa da Sociedade Brasileira de Medicina Tropical 28: 135-137, 1995.

19. Macaluso KR, Sonenschine DE, Ceraul SM, Azad AF. Rickettsial infection in Dermacentor variabilis (Acari: Ixodidae) inhibits transmission of a second Rickettsia. Journal of Medical Entomology 39: 808-813, 2002

20. Melles HHB, Colombo S, Silva MV. Febre Maculosa: Isolamento de Rickettsia em amostra de biópsia de pele. Revista do Instituto de Medicina Tropical de São Paulo 34: 37-41, 1992.

21. Nascimento EMM, Gehrke FS, Maldonado RA., Colombo S, Silva LJ, Schumaker TTS. Detection of brazilian spotted fever infection by polymerase chain reaction in a patient from the state of São Paulo. Memórias do Instituto Oswaldo Cruz 100: 277-279, 2005.

22. Nascimento EMM. Isolamento e detecção molecular de riquétsias do Grupo da Febre Maculosa, a partir de Amblyomma cajennense (Fabricius, 1787) e espécimens biológicos humanos, procedentes de áreas endêmicas do Estado de São Paulo. Dissertação de Mestrado, Universidade de São Paulo, São Paulo, SP, 2003.

23. Oliveira RP, Galvão MAM, Mafra CL, Chamone CB, Calic SB, Silva SU, Walker DH. Rickettsia felis in Ctenocephalides spp. Fleas, Brazil. Emerging Infectious Diseases 8: 317-319, 2002.

24. Phillip RN, Casper EA, Burgdorfer W, Gerloff RK, Hughes LE, Bell EJ. Serologic typing of rickettsiae of the spotted fever group by microimmunofluorescence. The Journal of Immunology 121: 1961-1968, 1978.

25. Policastro PF, Munderloh UG, Fischer ER, Hackstadt T. Rickettsia rickettsii growth and temperature-inducible protein expression in embryonic tick cell lines. Journal of Medical Microbiology 46: 839-845, 1997.

26. Raoult D, La Scola B, Enea M, Fournier PE, Roux V, Fenollar F, Galvão MAM, Lamballerie X. A flea-associates Rickettsia pathogenic for humans. Emerging Infectious Diseases 7: 2-11, 2001.

27. Regnery RL, Spruill CL, Plikaytis BD. Genotypic identification of rickettsiae and estimation of intraspecies sequence divergence for portions of two rickettsial genes. Journal of Bacteriology 173:1576-1586, 1991.

28. Roux V, Fournier PE, Raoult D. Differentiation of Spoted Fever Group Ricckettsiae sequencing and analysis of Restriction Fragment Length Polymorphism of PCR-Amplified DNA of the gene encoding the protein rOmpA. Journal of Clinical Microbiology 34:2058-2065, 1996

29. Stothard DR, Clark JB, Fuerst P. Ancestral divergence of Rickettsia bellii from the spotted fever and typhus groups of Rickettsia and antiquity of the genus Rickettsia. International Journal of Systematic Bacteriology 44: 798-804, 1994.

30. Travassos J, Vallejo A. Comportamento de alguns cavídeos (Cavia aperea e Hydrochoerus capybara) às inoculações experimentais do vírus da Febre Maculosa. Possibilidade desses cavídeos representarem o papel de depositários transitórios do vírus na natureza. Memórias do Instituto Butantã 15: 73-86, 1942 